\title{
Mitochondrial DNA and carcinogenesis (Review)
}

\author{
LUDMILA GRZYBOWSKA-SZATKOWSKA $^{1}$ and BRYGIDA SLASKA ${ }^{2}$ \\ ${ }^{1}$ Department of Oncology, Medical University of Lublin; \\ ${ }^{2}$ Department of Biological Bases of Animal Production, University of Life Sciences, Lublin, Poland
}

Received March 11, 2012; Accepted July 26, 2012

DOI: $10.3892 / \mathrm{mmr} .2012 .1027$

\begin{abstract}
The role of the mitochondria in the process of carcinogenesis has drawn researchers' attention since the discovery of respiratory deficit in cells, particularly those characterized by rapid proliferation. The deficit was assumed to stimulate further differentiation of the cells and initiate the process of neoplastic transformation. As many as $25-80 \%$ of somatic mutations in mitochondrial DNA (mtDNA) are found in various neoplasms. These mutations are considered to trigger the neoplastic transformation through shifts of cell energy resources, an increase in the mitochondrial oxidative stress and modulation of apoptosis. The question arises as to whether the mtDNA mutations precede a neoplasm or whether they are a result of changes and processes that take place during neoplastic proliferation.
\end{abstract}

\section{Contents}

1. Introduction

2. Mitochondrial DNA organization

3. Mitochondria and carcinogenesis

4. Mutations in the mitochondrial DNA in neoplasms

5. Homoplasmic and heteroplasmic mutations

6. The role of sense mutations

7. Conclusion

\section{Introduction}

The mitochondrial contribution to the neoplastic process was first suggested by Warburg (1) in 1932. He based his observation on a prevalence of anaerobic glycolysis in a neoplastic cell. The interest in the involvement of mitochondria in the process of carcinogenesis is also a result of the discovery of a respiratory deficit in the dividing cells, especially those characterized

Correspondence to: Dr Brygida Slaska, Department of Biological Bases of Animal Production, University of Life Sciences in Lublin, Akademicka 13, Lublin 20-950, Poland

E-mail: brygida.slaska@up.lublin.pl

Key words: cancer, carcinogenesis, mitochondrial DNA mutation by rapid proliferation (1-3). The oxidative deficit that arises apparently triggers further proliferation of the cells and causes a neoplastic transformation (3-5). Studies conducted in the 1970s suggested that the neoplastic transformation was a result of submolecular changes in the respiratory chain, which were considered the cause of the dismantling and reconstruction of the electron transport chain during the cell division process (3). After years of analyzing the role of the nuclear genome in the development of neoplasms, researchers returned to studying the mitochondria, focusing particularly on mitochondrial DNA (mtDNA) and its role in the neoplastic process (6-10).

The significance of the changes that occur in a mitochondrion in the process of carcinogenesis is indicated by the mutual relationship between the mev-1 mutation for SDHC complex II, the subunit C of Caenorhabditis elegans and an increased production of reactive oxygen species (ROS), which are important factors in the inactivation of proteins 16INK4a and TP53, involved in apoptosis and neoplastic proliferation $(5,11,12)$. The mitochondrial involvement in the process of carcinogenesis is confirmed by Lehtonen et al (13). They found a nuclear DNA (nDNA) mutation of fumarate hydratase in myoma and nephroma. In paranglioma and phaochromacytoma researchers described nDNA mutations in 3 out of 4 subunits of succinate dehydrogenase belonging to complex II of the respiratory chain system (14-16).

ROS disturbances in neoplastic cells are indicated by an increased level of metallothioneins in these cells (17). Reactive forms of oxygen are a potential agent inducing the synthesis of metallothioneins, the proteins responsible for, among other things, neoplastic cell resistance to pharmacological treatment. In our studies we have shown an elevated level of these proteins in the neoplastic cells of breast cancer. mtDNA is probably also implicated as suggested by its increased amount in peripheral blood leukocytes in colorectal cancer patients (18). Recent studies also suggest that changes of mtDNA content may be a prognostic factor for breast and lung cancer as well as for Hodgkin's lymphoma (19-21).

\section{Mitochondrial DNA organization}

mtDNA is made up of 16,569 nucleotide pairs $(22,23)$. Almost all of them are used to encode genetic information. In mtDNA, genes are encoded for two types of rRNA, 22 types of tRNA and 13 proteins involved in the process of oxidative phosphorylation (OXPHOS). Two strands of mtDNA are used for encoding a light and a heavy strand. Most of the genes are located in the heavy 
strand. The light strand contains only genes encoding 8 types of tRNA for proline, glutamine, serine, thyrosine, alanines, asparagines, cysteines, glycines and a complex I subunit 6 gene of the respiratory strand $(N D 6)(4,23)$. In the mitochondrial DNA there is a non-coding region (D-loop, displacement loop) $1,124 \mathrm{bp}$ (base pair) long, containing transcription and replication elements for the heavy and light strands of mtDNA. D-loop is a three-stranded structure made up of a double-stranded light strand and a single-stranded heavy strand. In that region, there are 2 hypervariable regions (HVR1 and HVR2), known as 'hot spots', since most of the mutations are thought to take place there. mtDNA is more prone to the mutagenic activity of free radicals than nDNA due to the lack of protective activity of histones in the former. In addition, the globular, coiled structure of mtDNA favors the binding of alkylating substances such as N-nitrozometylamine or benzopyrene. At the same time, those carcinogenes accumulate in the lipid membrane of the mitochondrion, in which the mtDNA and its replicating enzymes combine. Aflatoxin B1, responsible for liver cancer, is an example of a carcinogen that preferentially attacks mtDNA (24). All of the above listed factors make for more frequent mutations in mitochondrial than in nuclear DNA.

\section{Mitochondria and carcinogenesis}

The mitochondrial chain of electron transporting consists of 4 large complexes of respiratory enzymes, complex I, II, III and IV. Chronic exposure to ROS inactivates the iron-sulphuric center in complex I and II and III of the respiratory chain (25). There is a single-electron oxygen reduction during the electron transport to $\mathrm{Fe}-\mathrm{S}$ centers and thus an increased production of free radicals, i.e., the superoxide anion radical. Inhibition of electron flow by complex IV leads to increased escape of the electrons beyond the respiratory chain. A key role in free radical production is played by the transmembrane potential of the mitochondrial membrane occurring as a result of the electron flow and proton transportation out to the cytosol. The opening of non-specific mitochondrial channels present in the mitochondrial membrane causes a drop in the membrane potential, swelling of the mitochondrial membrane and activation of apoptosis, ATP synthesis block, and outflow of calcium ions, glutathione and $\mathrm{NAD}(\mathrm{P}) \mathrm{H}$ from the mitochondrial matrix (25-27). The opening of those mitochondria megachannels can be a result of increased influx of calcium ions to the mitochondrial matrix, increased exposure to free radicals or decreased energy production $(28,29)$. Increased influx of Ca ions to the mitochondria can cause neutralization of the proton gradient and thus contribute to a decrease in the membrane potential and an increase in the production of free radicals. Mutations within mtDNA affect genes that encode proteins of the respiratory chain complexes leading to a defective flow of electrons and protons through that membrane, which consequently increases its potential in neoplastic cells (30). Studies of cell apoptosis have shown that one of the earliest events initiating this process is a reduction of the inner mitochondrial membrane (IMM) potential to open its channels and enable the flow of proteins responsible for the induction of apoptosis $(31,32)$. Also, changes in the mitochondrial membrane affect the expression of nuclear genes that control the synthesis of the cytoplasmic membrane $(24,33)$.
Paragangliomas and papillary renal carcinoma mutations within succinate dehydrogenase (SDH) subunits B, C and D were detected as well as fumarate hydratase $(\mathrm{FH})$ of enzymes belonging to complex II of the respiratory chain and to the Krebs cycle. As a result of SDH and FH mutations and their aberrant functioning in the Krebs cycle, there is an increased level of these enzymes in the mitochondrium, which inhibits the catalytic activity of 2-oxoglutarate-dependent dioxygenases (34). These processes cause increased production of free radicals in the respiratory chain and further inhibition of dioxygenase function. Increased levels of FH and SDH activate the HIF-1 (hypoxia inducible factor) that blocks propyl hydroxylases leading to pseudohypoxia $(35,36)$ and as a result there is increased glycolysis and further inhibition of the Krebs cycle (37). It is also known that HIF-1 activation affects vascular epidermal growth factor and, thus, the process of angiogenesis. It is thought that the process of angiogenesis is necessary and strictly connected with tumorigenesis.

A normal cell prior to division can contain both mutated and normal wild-type mtDNA, a condition known as heteroplasmy. Most changes within the mtDNA of a neoplastic cell are of homoplasmic nature. Therefore, there have been attempts to explain the process of attaining the state of homoplasmy. As a result of an intramitochondrial selection, one type of mtDNA begins to dominate in the mitochondrion (this process is called functional advantage) (24). Another selection occurs at the cellular level, where one type of the mitochondria, containing one type of mtDNA, begins to dominate. During a division, the cell attempts to change the proportion between the mutated and normal mtDNA and to obtain homoplasmy, i.e., a domination or exclusive presence of only one type of mtDNA. This process is called replicative segregation $(24,38)$. During the process of cell division, a replicative segregation takes place with a selective advantage of the altered mitochondria. The period required for a replicative segregation to occur corresponds with the phase of a neoplastic transformation. The cell that contains mutated mtDNA is growth-privileged and starts to proliferate, yielding offspring that now contain only one type of mtDNA. This initiates tumor growth. The above is the classical model of a cell attempting to attain homoplasmy.

In a mathematical model, researchers suggest that homoplasmy is obtained through a random segregation of the mitochondria during the cell division process (39). The subsequent generations of descendant cells either maintain heteroplasmy or, through a genetic drift, arrive at homoplasmy $(39,40)$. The genetic drift can either cause elimination of rare variants of mtDNA or they can become established. This may be the case in neoplasia. The selective growth of cells with a mutated mtDNA may be a result of changes that occurred at the same time in nDNA, which stimulates these cells to proliferate and gives rise to a homogenic population in the previously altered mitochondria.

The appearance and degree of symptom severity in mitochondrial diseases depends on the proportion of normal and mutated DNA. The domination of a mutated mtDNA in a cell leads to disturbances of energy production in the process of OXPHOS, which results in cell and tissue damage. The clinical manifestation of these disturbances depends on the type of mtDNA damage, the degree of heteroplasmy and the sensitivity of a given tissue to cell respiration problems. The domination 
of the mutated mtDNA triggers symptoms of a progressive nature. The other mechanism of carcinogenesis involving mtDNA consists in the introduction of mtDNA fragments into the cellular nucleus $(41,42)$. In nDNA, sequences of mtDNA (pseudogenes) were found, which might have been translocated, as a result of autofagocytosis, to the nucleus in the course of evolution (43-45). The introduction of mtDNA molecules, particularly in the vicinity of promoters, may cause activation and expression of proto-oncogenes (33). This theory was confirmed in chemically-induced rat hepatomas, SV-40 virus modified fibroblasts and in the HT-1080 fibrosarcoma cell line, which demonstrated an increased number of copies of $C O I$, COII and COIII pseudogenes in the nuclear genome compared to normal cells (46). In the human HeLa cell line, fragments of mtDNA were found belonging to genes $12 \mathrm{~S}$ rRNA, cytochrome oxidase subunit I and III as well as NADH dehydrogenase introduced within the area of the c-myc gene (42).

An overexpression of proto-oncogenes causes protein synthesis damage, which leads to disturbances of cell growth and cancer progression. The involvement of both the mitochondria and mtDNA in carcinogenesis is possibly a complex process in which both mechanisms are active.

\section{Mutations in the mitochondrial DNA in neoplasms}

Mutations occurring in mtDNA can be beneficial or adaptive, neutral and harmful or pathogenic. Beneficial mutations are a result of human adaptation to the constantly changing environmental conditions, which has enabled humans to adapt to climate changes over centuries of evolution. The adaptative mutations that have taken place in the mtDNA of our ancestors migrating to other continents may have influenced human predisposition to certain diseases. One such example is haplogroup $\mathrm{J}$, where the presence of an additional mutation greatly increases the risk of blindness in Leber hereditary optic neuropathy $(47,48)$.

Typically, mtDNA is maternally inherited, which is why it does not undergo the process of recombination. Changes in mtDNA are a result of mutations that have taken place in germ or post-mitotic cells. It appears that only after these two mutations have occurred together and when there is a mutual reaction between them do they surface as mitochondrial diseases. Human neoplasms, both those running in the family as well as those occurring randomly, show spontaneous mutations in the nuclear genome. They are possible caused by insufficiency of a group of genes classified as mutator genes (mismatch repair genes; MMR) (49,50).

The first mtDNA mutation linked to a neoplasm was described in renal neoplasms. It involved gene $N D 1$ for oxidative phosphorylation (51). mtDNA somatic mutations (25-80\%) have been found in many neoplasms $(52,53)$. In $70 \%$ of colon cancer cases 1-3 mutations were found. In urinary bladder cancer $64 \%$ somatic mutations were present and in head and neck squamous cell carcinoma they constituted $46 \%$ (52). In lung cancer there were $43 \%$ mutations (52), in ovarian cancer $60 \%$, and $23 \%$ in papillomatous thyroid carcinoma (54). Our own pilot studies in breast cancer found polymorphisms (C14766T and G14905A) and mutations in cytochrome $b$ and mtRNA for the glutamic acid concerning position 14907 $(\mathrm{A} \rightarrow \mathrm{G}), 14906(\mathrm{C} \rightarrow \mathrm{T}), 14966(\mathrm{~A} \rightarrow \mathrm{G})$ and deletion CTCGCAC between 14681 and 14688 for mtRNA of the glutamic acid (55). Moreover, in breast cancer carcinoma, sequence analysis of 22 genes encoding mt-tRNA revealed 8 polymorphisms and 2 mutations detected in $34 \%$ of the patients (56). Transitions A15924G and A12308G took place only in neoplastic cells, but not in the blood, so the mutations can be attributed strictly to the neoplastic process. The authors suggest that its may affect the secondary and tertiary tRNA structure; polymorphisms may lead to mitochondrial dysfunction and contribute to revealing other changes in mtDNA (56).

To date, most of the mutations in mtDNA have been found in prostate cancer (57). In the European population, prostate cancer patients experienced more frequently occurring homoplasmic changes of missense type than healthy subjects (11 vs. 6.5\%) as far as neoplastic cells and lymphocytes in complex IV subunit I (COI) are concerned (57). This may suggest that they are not somatic changes, but ones that have already taken place in the germ-cell line. They described four missense-type mutations involving $C O I$ in prostate cancer: mutation $\mathrm{T} 6253 \mathrm{C}$ in patients belonging to the mitochondrial haplogroup $\mathrm{H}$; mutation C6340T in patients in haplogroup $\mathrm{J}$, T, L1 and N; G6261A in haplogroup $\mathrm{H}$ and N; and A6663G in LO and L2. Moreover, male patients who had changes in COI faced an increased risk of prostate cancer (57). The correlation between polymorphisms in $\mathrm{COI}$ and prostate cancer incidence is also confirmed by increased predisposition to the disease among African-American males compared with Americans of European descent. In the African population, the frequency of polymorphisms in $\mathrm{COI}$ is $17.4 \%$ compared with $6.5 \%$ in the European population of Americans (58). The polymorphisms in question are thought to be 7,385 and 7,146 occurring in the African line of haplogroup L0 and LOL1. In prostate cancer, there is also an increased expression of subunits encoded by the nucleus for complex IV, which may be a consequence of abrogating the effects of mtDNA mutations for that complex (59).

Mutations in COI, COII and COIII have been described both for solid tumors such as colon neoplasms (60) and for hematologic diseases such as sideroblastic anemia (61) or myelodysplastic syndrome $(62,63)$. In myelodysplastic syndrome they occurred in $\mathrm{COI}$ in $12 / 30$ patients and in $\mathrm{COII}$ in $12 / 20$ patients. The most frequent occurrence $(25 \%)$ involved region 7264; 15\% concerned region 7289 in COI. In COII, 40\% were found in region 7595 and 30\% in region 7594 (63).

Salas et al (64) take a critical approach toward the studies that find a definite link between mitochondrial mutations and neoplasia. According to them, most of the described homoplasmic mutations are adaptive polymorphisms not necessarily connected with a tumor.

In the pancreatic cancer cell line CEPAC (40), transitions in COI type T5999C and A6047G were described. These polymorphisms belong to subgroup U. Polymorphism T5999C occurs in haplogroup U3b, U4 and U9 and polymorphism A6047G in subgroup U1a $(65,66)$.

In the mitochondrial genome, the most changeable region is the displacement loop (D-loop). Most of the discovered point mutations are found there. In hepatomas there are $42.6 \%$ mutations, in stomach cancers $51.6 \%$, in colon cancers $40 \%$, in lung cancer $22.6 \%$ (67), in breast cancer $30 \%$ (68), in ovarian cancer 20\% (69), in Barrett's esophageal cancer $40 \%$ (70) and in squamous cell esophageal cancer $4 \%$ (71). 
Among the 50 patients with cancer originating from hepatic cells characterized by the presence of K-RAS onkogene and TP53 mutation in the tumor cells, 17 were diagnosed as having changes in mtDNA of the D-loop region 9 and in 5 of those patients the discovered changes correlated with changes in their blood serum. Conversely, no correlation was found between mutation occurrence and histopathologic analysis of a tumor, patient age or infection with the hepatitis B or hepatitis $\mathrm{C}$ virus or cirrhosis (72).

One of the mechanisms preventing the development of a neoplasm is cell aging (73). The epithelial cells of the mammary gland were found to have lost the ability to stop dividing and enter the plateau phase that leads to cell aging. These cells underwent frequent divisions and agglomerations of cells had formed which were entering a new phase of growth. Those cells had chromosomal abnormalities leading to disturbances of telomere structure, which account for breast cancer in mice (74). The presence of deletion 4,977 bp corresponds to cell aging. The discovery of this deletion in breast cancer cells as well as in the normal tissue of post-menopausal women attests to the beginning of a neoplastic transformation in already non-dividing, aging cells (74). It should be noted, however, that the deletion was more frequently met in nonneoplastic tissue (48.3\%) than in cancer cells (5\%) (75). Similar results were shown by $\mathrm{Wu}$ et al (7) in their study on stomach cancer. The mutation was visible in $3(9 \%)$ cases of cancer and in as many as $17(55 \%)$ samples of non-neoplastic tissue. Deletion 4,977 bp occurring between the positions 8470 and 13477 is connected with the process of cell aging and certain mitochondrial diseases. The deletion mainly concerns genes for mitochondrial tRNA. In that region there are also genes for cytochrome oxidase of subunit III (COIII), ATP6 and ND4, which may cause an impairment of OXPHOS.

Zhu et al (76) discovered at least one somatic mutation in $14 / 15$ cases of breast cancer. Most mutations (as many as $38 \%$ ) involved the D-loop region and $28 \%$ concerned the remaining regions. Out of 45 described mutations, 11 caused an amino-acid replacement in an encoded protein. The mutations concerned NADH dehydrogenase subunit 2 (G4665AG A60T), ATPase subunit 8 Fo (A8948GA K45E), COIII (T9885AT - F227I9) and cytochrome $b$ (G15755TG-G337W, T15783C-L346P, A15824G-T360A). In this study, 155 polymorphisms were found, $38 \%$ of which involved the D-loop and $62 \%$ involved encoding regions. In studies concerning changes in the mucous membrane of the stomach such as chronic inflammation of the mucous membrane of the stomach, gastrointestinal metaplasia, dysplasia and gastric cancer there was an accummulation of somatic changes in mtDNA, i.e. 12.5, 20 , 25 and $38.2 \%$, respectively (77). A rising number of mutations in mtDNA indicates their early role in gastric carcinogenesis.

The role of somatic mutations in mtDNA for the progression of neoplasms is still under investigation. It is quite possible that mutations in conservative nucleotides, replication sites, transcription promoters or transcription binding sites can disturb the amount of the mitochondrial transcript and mature proteins, thereby impairing the overall activity of the mitochondria. On the other hand, mutations in mtDNA-encoded genes of OXPHOS do not necessarily cause changes in the encoded protein. In pancreatic cancer, $26 / 49$ changes were silent changes within expressed sequences. The remaining
23 mutations within coding sequences, or regulatory sequences, exhibit potential functional significance and concerned rRNA, $\mathrm{NADH}$ dehydrogenase for subunits NDI-ND5, cytochrome $b$, complex IV of cytochrome $c$ oxidoreductase, ATP synthetase subunit 6 and 8 and the D-loop (40). Thus far, no mutations characteristic of any particular type of neoplasm have been identified.

Essentially, these mutations should first and foremost cause a neoplastic transformation by changing the cell energy resources, increasing mitochondrial oxidative stress and modulating apoptosis. There is also a question of whether the mutations present in the mitochondrial DNA are primary to the neoplasm or whether they are a consequence of changes and processes characteristic of a neoplasia. The former is supported by the fact that they appear as clinical symptoms after a long time since a mutation has taken place (when the mutated DNA begins to dominate) and a progressive, slow character of those symptoms. In spite of extensive studies, the involvement of the mitochondria in the process of carcinogenesis remains unclear.

Tseng et al (68) argue that the appearance of mutations in the D-loop region in breast cancer (30\%) corresponds with a shorter time to progression of the disease compared with a control without those mutations. The mutations were more frequent in women $>50$ years of age and in patients without the expression of hormonal receptors $(\mathrm{P}=0.024)$. In studies on stomach cancer, changes in the D-loop region did not correspond to any pathological and clinical features. However, the authors suggest that somatic mutations and deletions in mtDNA are connected with carcinogenesis and progression of the disease since they occurred mainly in the ulcerative, infiltrating and diffused stomach cancer $(77,78)$.

Another study confirmed that in gastrointestinal neoplasms there was a high frequency of mutations independent of the cancer location: $14 \%$ (7/51) in esophageal cancer, 15\% (14/94) in stomach cancer and $8 \%(11 / 133)$ in colon cancer (79). It did not show, however, a correlation of mutation frequency and age, gender, depth of neoplastic infiltration or the number of lymphatic nodes involved (79). In nasopharyngeal neoplasms, however, a significant correlation $(\mathrm{P}=0.01)$ was found between smoking and the occurrence of mutations in the D-loop region. No correlation, though, was found between patient prognosis and the response to neoadjuvant therapy (80).

In breast cancer, Tan et al (81) examined 19 tumors, where mostly homoplasmic changes were found. Only one case displayed heteroplasmic changes although we cannot exclude contamination with normal tissue. The heteroplasmic change concerned position C16147T of the D-loop region. Heteroplasmic changes normally refer to neoplastic cells. When analyzing a tumor, it is hard to definitely determine the presence or absence of normal cells in the tumor in the case of heteroplasmy. Studying the tissue surrounding a tumor we cannot be completely certain there are no neoplastic cells present. Blood heteroplasmy of gene encoding tRNA-Thr was diagnosed in breast cancer carcinoma (56). The polymorphism 15924A could be a result of contamination of the blood with circulating neoplastic cells. This polymorphism was accompanied by polymorphism $12308 \mathrm{G}$, also present only in the patient's blood. The authors suggest that these mutations are closely associated with cancer cells (56). 
Tan et al (81) described 4 somatic changes for OXPHOS in breast cancer. In three cases they involved NADH dehydrogenase subunit 2 (silent mutations) and ATP synthase subunit 6 in T9131C. The latter is listed in the database as a polymorphism. It is hard to conclude if it plays any part in carcinogenesis. Two other polymorphisms are thought to be linked to increased risk of breast and endometrial cancer. Polymorphism $16189(\mathrm{~T} \rightarrow \mathrm{C})$ is thought to be present in endometrial cancer (82). Polymorphism $10398(\mathrm{G} \rightarrow \mathrm{A})$ occurring in haplogroup $\mathrm{N}$ concerning ND3 gene changing codon A114T is thought to increase the risk of breast cancer in AfricanAmerican women $(83,84)$. No such dependency was found in American white women, although more frequent occurrence of this polymorphism was found in Polish women with breast cancer compared with the control (85). Similar results were obtained by Hindu researchers in studies of breast cancer in Hindi women (86). Cells with 10398A polymorphism have a decreased $\mathrm{pH}$ in the mitochondria matrix and a decreased level of $\mathrm{Ca}^{2+}$ compared with $10398 \mathrm{G}$ cells (85). It is thought that the occurrence of polymorphism 10398 contributes to the decrease in cellular free radicals, which can cause somatic mutations within DNA. However, Setiawan et al (87) deny a correlation between an increased risk of breast cancer in African women and polymorphism 10398. A critical approach to a relationship between mutations or polymorphisms and neoplasms is also taken by Salas et al (64). They claim that most of the assumed cancer-related mutations described are rare polymorphisms and they do not have to be connected with neoplasia.

The polymorphism in COIII described in the literature at position A9477G and causing a change of valine into isoleucine, is conducive to migrenous stroke fits, especially if it occurs together with the tRNA polymorphism 12308 for leucine or 16sRNA polymorphism $2706(88,89)$. This polymorphism is connected with mitochondrial haplogroup U5 and is not considered to be neutral to the functioning of the protein (90). It involves a replacement of a conservative amino-acid here, i.e. valine, by isoleucine. Valine in PSSM reaches the value of 5 and isoleucine the value of 2 .

Brandon et al (9) maintain that the occurrence in neoplasms of polymorphisms typical of particular mitochondrial haplogroups can be a result of acquiring by those cells the same mtDNA mutations as during the migration of our ancestors from Africa to other continents. These mutations are supposedly a consequence of the neoplastic cell adaptation to a changing environment during the process of carcinogenesis. It is likely that there is an activation of similar mechanisms taking place as during the human migrations. They also take into account that some of the mutations or polymorphisms which seem to be specific to a neoplasm and which are described by different researchers, are, in reality, polymorphisms typical of a given population (9). In the European population we usually deal with subgroups H, I, J, K U of mtDNA depending on the polymorphisms concerned (91). The occurrence of those polymorphisms can contribute to susceptibility to certain diseases, especially when they accompany additional changes in mtDNA. It has been proven that the presence of mutation 14484 in haplogroup $\mathrm{J}$ is connected with an 8-fold increase of LHON risk (92). Change 4336C in haplogroup $\mathrm{H}$ is thought to be sufficient for late-onset Alzheimer's incidence (93). The appearance of type A12308G polymorphism in mitochondrial haplogroup $\mathrm{U}$ favors more frequent fits in people suffering from migraines. In mitochondrial diseases, most mutations concern genes for tRNA, considered to be hot spots in those cases $(94,95)$. Contrary to mitochondrial diseases, mutations in genes encoding mitochondrial tRNA are not hot spots for breast cancer (56).

\section{Homoplasmic and heteroplasmic mutations}

In colon cancer, $70 \%$ ROS-induced mutations have been described which involved a replacement of type $\mathrm{T}$ by $\mathrm{C}$ and type $\mathrm{G}$ by $\mathrm{A}(60)$. Those were mostly somatic and homoplasmic mutations similar to ovarian cancer (69).

Somatic cells contain hundreds to several thousand mitochondria, which, in turn contain 1-10 copies of mtDNA genes. Due to its structure, mtDNA often undergoes spontaneous mutations many of which are considered to be polymorphisms. It is hard to explain how, among the great number of mtDNA haplotypes, one type begins to dominate which is characteristic of a neoplastic cell and which is usually discovered as homoplasmy in tissue lesions or aging. Numerous studies of hetero- and homoplasmy in mtDNA point to a more frequent than previously thought occurrence of heteroplasmy which is still not evidence of its pathological character (64). Mitochondrial DNA seems to be unique in this respect and the occurrence and degree of heteroplasmy may depend on the type of tissue. Point mutations in neoplasms are usually homoplasmic while heteroplasmy, often seen in tumors or normal aging cells, typically involves deletions. A question arises whether homoplasmic mutations occurring in mtDNA arise de novo or whether they have been in the cell from the beginning. In a study conducted by Polyak et al (60), the formation of homoplasmic mtDNA was closely observed. A fusion of the DLD1 cell line resistant to geneticine and the HCT116 cell line resistant to hygromycine was implemented. In the new cell hybrids, following several divisions there was a prevalence of cells containing mtDNA from the DLD1 cell line and the final result was the presence of only the mtDNA of DLD1 resistant to geneticine. What happened here was a selective dominance of one type of mtDNA and to homoplasmy. It seems that the mutated mitochondrial DNA is replicated to a greater extent than the wild-type DNA. During carcinogenesis we deal with thousands of more cell generations. The process continues long enough for neoplastic cells to allow the 'wild-type mtDNA' to be replaced by the mutated one.

There is a recent assumption (a bottleneck hypothesis) that homoplasmy or heteroplasmy in the neoplastic cells occur when the descendant cells receive a group of mitochondria of the same haplotype during mitosis (96). Through a repeated division of the mitochondria containing two types of the mitochondrial haplotype: the wild-type and the mutated one, (an agglomeration of) mitochondria of the same haplotype are formed inside of the cytoplasmic domains $(40,96)$. As long as there is predominance of wild-type mitochondria in a normal cell, heteroplasmy is not detectable. During mitosis, a segregation of the mitochondrial genome probably takes place in a cell. Each of the two daughter cells receives the mitochondria containing only one type of mtDNA. The result is that one daughter cell contains the wild-type mtDNA while the other one has the mutated type. The cell containing the mutated mtDNA begins the process of transformation and expansion. 
Heteroplasmy or homoplasmy, therefore, arises at the very beginning of cancer development. During the neoplasm expansion new variants of heteroplasmy can be formed in a cell (96).

Numerous studies have shown that in the case of epithelial tissue neoplasms, at least one homoplasmic mtDNA mutation is present $(72,97)$. Further cell divisions connected with the transformation of the cell into a neoplastic one are supposed to both enable further mutations and facilitate expansion. This is why we should expect an increased number of mtDNA mutations in tumors compared with the normal tissue (39). This is also why in the majority of neoplastic tumors, changes in mtDNA are of homoplasmic nature.

It also appears that due to the great number of mutations occurring in it in neoplasms, mtDNA, such as nDNA, can become a neoplastic marker. Previously, ways of detecting mutations in the urine (52), blood (72) or saliva (52) of cancer patients have been reported. In head and neck neoplasms as many as $67 \%$ of changes detected in the tumor corresponded with changes in the patients' saliva (52). The homoplasmic changes detected in the bronchial discharge corresponded in 8 out of 10 cases with changes in the bronchial tumor compared with a lack of such changes in the normal tissue (52).

Zhu et al (76) compared the detectability of mtDNA mutations in samples obtained through a fine-needle aspiration biopsy and in postoperative tissue from breast cancer. In the postoperative samples they found at least one mutation. The biopsy samples contained mtDNA mutations in 15/19 cases. Four patients had no mutations (there were no false positive results), which means that each of the changes present in the bioptate was also present in the postoperative tumor sample.

\section{The role of sense mutations}

It is thought that the mitochondrial replication is a controlled process and a signal coming from the functionally altered mitochondria provokes an excessive replication to improve the functioning of the cell (98). The phenomenon suggests that each of the mtDNA mutations affects their functioning. However, it is difficult to explain how silent mutations, which do not cause changes in the protein, affect the functioning of the mitochondria. There are two theories.

The first one assumes that these sense mutations carry with them some extremely hard to detect, unidentified mutations, which lead to a selective domination of the mutated genome and a replacement of the wild-type by it. It is possible that when the mitochondrial genome does not undergo recombination, a mutation is to some extent established, resulting in genetic hitch-hiking, and causes heteroplasmy followed by homoplasmy in the following generations $(96,99,100)$.

The second theory maintains that the mitochondrion itself controls its own replication. When its functioning begins to change, such a 'mutated' mitochondrion starts to replicate intensively, whereby it begins to dominate in the cell $(40,100)$.

It is also unclear how these sense mtDNA mutations influence and modulate the very process of translation, particularly when this process in mtDNA differs slightly from the cytoplasmic one (mtDNA mRNAs do not have 5' and 3' UTRs) (9).

It appears that apart from mtDNA mutations the key factor is an additional occurrence of polymorphisms, which can cause a very subtle, almost undetectable, elevation of free radical production. It cannot be excluded that polymorphisms might be those additional changes accompanying the sense mutations which might favor the selective domination of the mutated mtDNA (96).

\section{Conclusion}

Mitochondria play a significant role in oxidative phosphorylation and apoptosis. Changes in mtDNA may disturb these processes and lead to the abnormal function of the cell. These abnormalities appear to be one of the general features of malignant cells. Up to $80 \%$ of somatic mutations in mtDNA are found in various neoplasms. However, whether they are a consequence or a cause of cancer remains unclear. Nevertheless, if the supporting alterations in mtDNA occur at the early stage of carcinogenesis, they may be used as markers for the early detection of cancer.

\section{References}

1. Warburg O (ed): The Metabolism of Tumors. Arnold Constable, London, UK, 1932.

2. Warburg O: On the origin of cancer cells. Science 123: 309-314, 1956.

3. Szent-Gyorgyi A: Electronic biology and cancer. In: Search and Discovery: A Tribute to Albert Szent-Gyorgyi. Kaminer B (ed). Academic Press, New York, pp329-335, 1977.

4. Krieg RC, Knuechel R, Schiffmann E, Liotta LA, Petricoin EF and Herrmann PC: Mitochondrial proteome: cancer-altered metabolism associated with cytochrome c oxidase subunit level variation. Proteomics 4: 2789-2795, 2004.

5. Ishii N, Ishii T and Hartman PS: The role of the electron transport gene SDHC on lifespan and cancer. Exp Gerontol 41: 952-656, 2006.

6. Pejovic T, Ladner D, Intengan M, Zheng K, Fairchild T, Dillon D, Easley S, Dillon D, Marchetti D, Schwartz P, et al: Somatic D-loop mitochondrial DNA mutations are frequent in uterine serous carcinoma. Eur J Cancer 40: 2519-2524, 2004.

7. Wu CW, Yin PH, Hung WY, Li AF, Li SH, Chi CW, Wei YH and Lee HC: Mitochondrial DNA mutations and mitochondrial DNA depletion in gastric cancer. Gene Chromosome Canc 44: 19-28, 2005.

8. Zanssen S and Schon EA: Mitochondrial DNA mutations in cancer. 65 PLoS Med 2: e401, 2005.

9. Brandon M, Baldi P and Wallach DC: Mitochondrial mutations in cancer. Oncogene 25: 4647-4662, 2006.

10. Czarnecka M and Bartnik E: Mitochondrial DNA mutations in tumors. In: Cellular Respiration and Carcinogenesis. Apte SP and Sarangarajan R (eds). Humana Press, New York, pp119-130, 2009.

11. Adachi H, Fujiwara Y and Ishii N: Effects of oxygen on protein carbonyl and aging in Caenorhabditis elegans mutants with long (age-1) and short (mev-1) life spans. J Gerontol A Biol Sci Med Sci 53: B240-B244, 1998.

12. Senoo-Matsuda N, Yasuda K, Tsuda M, Ohkubo T, Yoshimura S, Nakazawa H, Hartman PS and Ishii N: A defect in the cytochrome b large subunit in complex II causes both superoxide anion overproduction and abnormal energy metabolism in Caenorhabditis elegans. J Biol Chem 276: 41553-41558, 2001.

13. Lehtonen R, Kiuru M, Vanharanta S, Sjöberg J, Aaltonen LM, Aittomäki K, Arola J, Butzow R, Eng C, Husgafvel-Pursiainen K, et al: Biallelic inactivation of fumarate hydratase $(\mathrm{FH})$ occurs in nonsyndromic uterine leiomyomas but is rare in other tumors. Am J Pathol 164: 17-22, 2004.

14. Benn DE, Croxson MS, Tucker K, Bambach CP, Richardson AL, Delbridge L, Pullan PT, Hammond J, Marsh DJ and Robinson BG: Novel succinate dehydrogenase subunit B (SDHB) mutations in familial phaeochromocytomas and paragangliomas, but an absence of somatic SDHB mutations in sporadic phaeochromocytomas Oncogene 22: 1358-1364, 2003.

15. Bayley JP, Devilee P and Taschner PE: The SDH mutation database: an online resource for succinate dehydrogenase sequence variants involved in pheochromocytoma, paraganglioma and mitochondrial complex II deficiency. BMC Med Genet 16: 39, 2005. 
16. Bayley JP, van Minderhout I, Weiss MM, Jansen JC, Oomen PH, Menko FH, Pasini B, Ferrando B, Wong N, Alpert LC, et al: Mutation analysis of SDHB and SDHC: novel germline mutations in sporadic head and neck paraganglioma and familial paraganglioma and/or pheochromocytoma. BMC Med Genet 7: $1,2006$.

17. Floriańczyk B and Grzybowska L: Metallothionein and zinc level in breast cancer. J Tumor Marker Oncol 14: 23-27, 1999.

18. Qu F, Liu X, Zhou F, Yang H, Bao G, He X and Xing J: Association between mitochondrial DNA content in leukocytes and colorectal cancer risk. Cancer 117: 3148-3155, 2011.

19. Yu M, Zhou Y, Shi Y, Ning L, Yang Y, Wei X, Zhang N, Hao X and Niu R: Reduced mitochondrial DNA copy number is correlated with tumor progression and prognosis in Chinese breast cancer patients. IUBMB Life 59: 450-457, 2007.

20. Lan Q, Lim U, Liu CS, Weinstein SJ, Chanock S, Bonner RM, Virtamo R, Albanes D and Rothman N: A prospective study of mitochondrial DNA copy number and risk of non-Hodgkin lymphoma. Blood 112: 4247-4249, 2008.

21. Hosgood HD III, Liu CS, Rothman N, Weinstein SJ, Bonner MR, Shen M, Lim U, Virtamo J, Cheng WL, Albanes D and Lan Q: Mitochondrial DNA copy number and lung cancer risk in a prospective cohort study. Carcinogenesis 31: 847-849, 2010.

22. Anderson S, Bankier AT, Barrell BG, de Bruijn MHL, Coulson AR, Drouin J, Eperon IC, Nierlich DP, Roe BA, Sanger F, et al: Sequence and organization of the human mitochondrial genome. Nature 290: 457-465, 1981.

23. Andrews RM, Kubacka I, Chinnery PF, Lightowlers RN, Turnbull DM and Howell N: Reanalysis and revision of the Cambridge reference sequence for human mitochondrial DNA Nat Genet 23: 147, 1999.

24. Augenlicht LH and Heerdt BG: Mitochondria: integrators in tumorigenesis? Nat Genet 28: 104-105, 2001.

25. Wallace DC: Mitochondrial diseases in man and mouse. Science 283: 1482-1488, 1999

26. Kanno T, Sato EE, Muranaka S, Fujita H, Fujiwara T, Utsumi T, Inoue $\mathrm{M}$ and Utsumi $\mathrm{K}$ : Oxidative stress underlies the mechanism for $\mathrm{Ca}(2+)$-induced permeability transition of mitochondria. Free Radic Res 38: 27-35, 2004

27. Lyamzaev KG, Izyumov DS, Avetisyan AV, Yang F Pletjushkina OY and Chernyak BV: Inhibition of mitochondrial bioenergetics: the effects on structure of mitochondria in the cell and on apoptosis. Acta Biochim Pol 51: 553-562, 2004.

28. Levraut J, Iwase H, Shao ZH, Vanden Hoek TL and Schumacker PT: Cell death during ischemia: relationship to mitochondrial depolarization and ROS generation. Am J Physiol Heart Circ Physiol 284: 549-558, 2003.

29. Petrosillo G, Ruggiero FM, Pistolese M and Paradies G: $\mathrm{Ca} 2+-$ induced reactive oxygen species production promotes cytochrome $\mathrm{c}$ release from rat liver mitochondria via mitochondrial permeability transition (MPT)-dependent and MPT-independent mechanisms: role of cardiolipin. J Biol Chem 279: 53103-53108, 2004

30. Modica-Napolitano JS, Kulawiec M and Singh KK: Mitochondria and human cancer. Curr Mol Med 7: 121-131, 2007.

31. Chen LB: Mitochondrial membrane potential in living cells Annu Rev Cell Biol 4: 155-181, 1988.

32. Chen Q, Chai YC, Mazumder S, Jiang C, Macklis RM, Chisolm GM and Almasan A: The late increase in intracellular free radical oxygen species during apoptosis is associated with cytochrome c release, caspase activation and mitochondrial dysfunction. Cell Death Differ 10: 323-334, 2003.

33. Baggetto LG: Mitochondrie et cancer. Reg Biochim 5: 48-54, 1992.

34. Kaelin WG Jr: SDH5 mutations and familial paraganglioma: somewhere Warburg is smiling. Cancer Cell 16: 180-182, 2009.

35. Dahia PLM, Ross K, Wright ME, Hayashida CY, Santagata S,Barontini M, Kung AL, Sanso G, Powers JF, Tischler AS, et al: A HIF1 $\alpha$ regulatory loop links hypoxia and mitochondrial signals in pheochromocytomas. PLoS Genet 1 : $72-80,2005$

36. Isaacs JS, Jung YJ, Mole DR, Lee S, Torres-Cabala C, Chung YL, Merino M, Trepel J, Zbar B, Toro J, et al: HIF overexpression correlates with biallelic loss of fumarate hydratase in renal cancer: novel role of fumarate in regulation of HIF stability. Cancer Cell 8: 143-153, 2005.

37. Baysal BE: Role of mitochondrial mutations in cancer. Endocr Pathol 17: 203-212, 2006.

38. Green DR and Reed JC: Mitochondria and apoptosis. Science 281: 1309-1316, 1998
39. Coller HA, Khrapko K, Bodyak ND, Nekhaeva E, Herrero-Jimenez P and Thilly WG: High frequency of homoplasmic mitochondrial DNA mutations in human tumors can be explained without selection. Nat Genet 28: 147-150, 2001

40. Jones JB, Song JJ, Hempen PM, Parmigiani G, Hruban RH and Kern SE: Detection of mitochondrial DNA mutations in pancreatic cancer offers a 'mass'-ive advantage over detection of nuclear DNA mutations. Cancer Res 61: 1299-1304, 2001.

41. Reid R: Can migratory mitochondria DNA activate oncogenes? Trends Biochem Sci 8: 190-191, 1983.

42. Shay JW and Werbin H: New evidence for the insertion of mitochondrial DNA into the human genome: significance for cancer and aging. Mutat Res 275: 227-235, 1992.

43. Wallace DC: Mitochondrial DNA sequence variation in human evolution and disease. Proc Natl Acad Sci USA 91: 8739-8746, 1994

44. Collura RV and Stewart CB: Insertions and duplications of mtDNA in the nuclear genomes of Old World monkeys and hominoides. Nature 378: 485-489, 1995.

45. Zischler H, Geisert $\mathrm{H}$ and Castresana J: A hominoid-specific nuclear insertion of the mitochondrial D-loop: implications for reconstructing ancestral mitochondrial sequences. Mol Biol Evol 15: 463-469, 1998.

46. Corral M, Paris B, Baffet G, Tichonicky L, Guguengillouzo C, Kruh $\mathrm{J}$ and Defer $\mathrm{N}$ : Increased level of the mitochondrial NDS transcript in chemically induced rat hepatomas. Exp Cell Res 184: 158-166, 1989.

47. Brown MD, Starikovskaya YB, Derbeneva O, Hosseini S, Allen JC, Mikhailovskaya IE, Sukernik RI and Wallace EC: The role of mtDNA background in disease expression: a new primary LHON mutation associated with Western European halogroup J. Hum Genet 110: 130-138, 2002.

48. Koilkonda RD and Guy J: Leber's Hereditary Optic NeuropathyGene Therapy: From Benchtop to Bedside. J Ophthalmol: 179412, 2011

49. de la Chapelle A and Peltomaki P: The genetics of hereditary common cancers. Curr Opin Genet Dev 8: 298-303, 1998.

50. Peltomaki P: DNA mismatch repair and cancer. Rev Mutat Res 488: 77-85, 2001

51. Welter C, Kovacs G, Seitz G and Blin N: Alteration of mitochondrial DNA in human oncocytomas. Gene Chromosome Canc 1: 79-82, 1989.

52. Fliss MS, Usadel H, Caballero OL, Wu L, Buta MR, Eleff SM, Jen J and Sidransky D: Facile detection of mitochondrial DNA mutations in tumors and bodily fluids. Science 287: 2017-2019, 2000.

53. Parrella P, Xiao Y, Fliss M, Sanchez-Cespedes M, Mazzarelli P and Rinaldi M: Detection of mitochondrial DNA mutations in primary breast cancer and fine-needle aspirates. Cancer Res 61: 7623-7626, 2001

54. Yeh JJ, Lunetta KL, van Orsouw NJ, Moore FD Jr, Mutter GL, Vijg J, Dahia PL and Eng C: Somatic mitochondrial DNA (mtDNA) mutations in papillary thyroid carcinomas and differential mtDNA sequence variants in cases with thyroid tumours. Oncogene 19: 2060-2066, 2000.

55. Szatkowska L, Rzymowska J, Brzozowska A and Mazurkiewicz M: Mutations in the mitochondrial DNA (mtDNA) in breast cancer tissue. Breast 12: 27, 2005

56. Grzybowska-Szatkowska L and Slaska B: Polymorphisms in genes encoding mt-tRNA in female breast cancer in Poland. Mitochondrial DNA 23: 106-111, 2012.

57. Petros JA, Baumann AK, Ruiz-Pesini E, Amin MB, Sun CQ, Hall J, Lim S, Issa MM, Flanders WD, Hosseini SH, et al: MtDNA mutations increase tumorigenicity in prostate cancer. PNAS 102: 719-724, 2005.

58. Ruiz-Pesini E, Mishmar D, Brandon M, Procaccio V and Wallace DC: Effects of purifying and adaptive selection on regional variation in human mtDNA. Science 303: 223-226, 2004.

59. Herrmann PC, Gillespie JW, Charboneau L, Bichsel VE, Paweletz CP, Calvert VS, Kohn EC, Emmert-Buck MR, Liotta LA and Petricoin EF: Mitochondrial proteome: Altered cytochrome c oxidase subunit levels in prostate cancer. Proteomics 3 : 1801-1810, 2003.

60. Polyak K, Li Y, Zhu H, Lengauer C, Willson JKV, Markowitz SD, Trush MA, Kinzler KW and Vogelstein B: Somatic mutations of the mitochondrial genome in human colorectal tumours. Nat Genet 20: 291-293, 1998.

61. Gattermann N, Retzlaff S, Wang YL, Hofhaus G, Heinisch J, Aul C and Schneider W: Heteroplasmic point mutations of mitochondrial DNA affecting subunit I of cytochrome c oxidase in two patients with acquired idiopathic sideroblastic anemia. Blood 90: 4961-4972, 1997. 
62. Gattermann N, Wulfert M and Hofhaus G: How frequent is mutation in the mitochondrial cytochrome $\mathrm{c}$ oxidase gene in patients with myelodysplastic syndromes? Br J Haematol 119: 1139-1140, 2002.

63. Reddy PL, Shetty VT, Dutt D, York A, Dar S, Mundle SD, Allampallam K, Alvi S, Galili N, Saberwal GS, et al: Increased incidence of mitochondrial cytochrome c-oxidase gene mutations in patients with myelodysplastic syndromes. Brit J Haematol 116: 564-575, 2002

64. Salas A, Yao YG, Macaulay V, Vega A, Carracedo A and Bandelt HJ: A critical reassessment of the role of mitochondria in tumorigenesis. PLoS Med 11: e296, 2005

65. Achilli A, Rengo C, Magri C, Battaglia V, Olivieri A, Scozzari R, Cruciani F, Zeviani M, Briem E, Carelli V, et al: The molecular dissection of mtDNA haplogroup H confirms that the FrancoCantabrian glacial refuge was a major source for the European gene pool. Am J Hum Genet 75: 910-918, 2004.

66. Achilli A, Rengo C, Battaglia V, Pala M, Olivieri A, Fornarino S, Magri C, Scozzari R, Babudri N, Santachiara-Benerecetti AS, et al: Saami and Berbers - an unexpected mitochondrial DNA link. Am J Hum Genet 76: 883-886, 2005

67. Lee HC, Yin PH, Lin JC, Wu CC, Chen CY, Wu CW, Chi CW, Tam TN and Wei YH: Mitochondrial genome instability and mtDNA depletion in human cancers. Ann NY Acad Sci 1042: 109-122, 2005.

68. Tseng LM, Yin PH, Chi CW, Hsu CY, Wu CW, Lee LM, Wei YH and Lee HC: Mitochondrial DNA mutations and mitochondrial DNA depletion in breast cancer. Genes Chromosomes Cancer 45: 629-638, 2006

69. Liu VWS, Shi HH, Cheung ANY, Chiu PM, Leung TW, Nagley P, Wong LC and Ngan HYS: High incidence of somatic mitochondrial DNA mutations in human ovarian carcinomas. Cancer Res 61: 5998-6001, 2001.

70. Miyazono F, Schneider PM, Metzger R, Warnecke-Eberz U, Baldus SE, Dienes HP, Aikou T and Hoelscher AH: Mutations in the mitochondrial DNA D-Loop region occur frequently in adenocarcinoma in Barrett's esophagus. Oncogene 21: 3780-3783, 2002.

71. Hibi K, Nakayama H, Yamazaki T, Takase T, Taguchi M, Kasai Y, Ito K, Akiyama S and Nakao A: Mitochondrial DNA alteration in esophageal cancer. Int J Cancer 92: 319-321, 2001.

72. Okochi O, Hibi K, Uemura T, Inoue S, Takeda S and Kaneko T: Detection of mitochondrial DNA alterations in the serum of hepatocellular carcinoma patients. Clin Cancer Res 8: 2875-2878, 2002

73. Aure K, Fayet G, Leroy JP, Lacène E, Romero NB and Lombès A: Apoptosis in mitochondrial myopathies is linked to mitochondrial proliferation. Brain 129: 1249-1259, 2006.

74. Romanov SR, Kozakiewicz BK, Holst CR, Stampfer MR, Haupt LM and Tlsty TD: Normal human mammary epithelial cells spontaneously escape senescence and acquire genomic changes. Nature 409: 633-637, 2001.

75. Tseng LM, Yin PH, Tsai Y-F, Chi CW, Wu CW, Lee LM and Lee HC: Association between mitochondrial DNA 4,977 bp deletion and $\mathrm{NAD}(\mathrm{P}) \mathrm{H}$ : Quinone oxidoreductase $1 \mathrm{C} 609 \mathrm{~T}$ polymorphism in human breast tissues. Oncol Rep 21: 1169-1174, 2009.

76. Zhu W, Qin W, Bradley P, Wessel A, Puckett CL and Sauter ER Mitochondrial DNA mutations in breast cancer tissue and in matched nipple aspirate fluid. Carcinogenesis 26: 145-152, 2005

77. Ling XL, Fang DC, Wang RQ, Yang SM and Fang L: Mitochondrial microsatellite instability in gastric cancer and its precancerous lesions. World J Gastroenterol 15: 800-803, 2004.

78. Burgart LJ, Zheng J, Shu Q, Strickler JG and Shibata D: Somatic mitochondrial mutation in gastric cancer. Am J Pathol 147: $1105-1111,1995$

79. Kose K, Hiyama T, Tanaka S, Yoshihara M, Yasui W and Chayama K: Somatic mutations of mitochondrial DNA in digestive tract cancers. J Gastroenterol Hepatol 20: 1679-1684 2005.

80. Ličvre A, Blons H, Houllier A M, Laccourreye O, Brasnu D, Beaune P and Laurent-Puig P: Clinicopathological significance of mitochondrial D-Loop mutations in head and neck carcinoma. Brit J Cancer 94: 692-697, 2006.
81. Tan DJ, Bai RK and Wong LJC: Comprehensive scanning of somatic mitochondrial DNA mutations in breast cancer. Cancer Res 62: 972-976, 2002

82. Liu VW, Wang Y, Yang HJ, Tsang PC, Ng TY, Wong LC, Nagley P and Ngan HY: Mitochondrial DNA variant $16189 \mathrm{~T}>C$ is associated with susceptibility to endometrial cancer. Hum Mutat 22: 173-174, 2003.

83. Canter JA, Kallianpur AR, Parl FF and Millikan RC: Mitochondrial DNA G10398A polymorphism and invasive breast cancer in African-American women. Cancer Res 65: 8028-8033, 2005

84. Mims MP, Hayes TG, Zheng S, Leal SM, Frolov A, Ittmann MM, Wheeler TM and Prchal JT: Mitochondrial DNA G10398A polymorphism and invasive breast cancer in African-American women. Cancer Res 66: 1880; author reply 1880-1881, 2006.

85. Czarnecka AM, Krawczyk T, Zdrożny M, Lubiński J, Arnold RS, Kukwa W, Ścińska A, Golik P, Bartnik E and Petros JA: Mitochondrial NADH-dehydrogenase subunit 3 (ND3) polymorphism (A10398G) and sporadic breast cancer in Poland. Breast Cancer Res Treat 121: 511-518, 2010.

86. Darvishi K, Sharma S, Bhat AK, Rai E and Bamezai RN: Mitochondrial DNA G10398A polymorphism imparts maternal Haplogroup $\mathrm{N}$ a risk for breast and esophageal cancer. Cancer Lett 249: 249-255, 2007.

87. Setiawan VW, Chu LH, John EM, Ding YC, Ingles SA, Bernstein L, Press MF, Ursin G, Haiman CA and Neuhausen SL: Mitochondrial DNA G10398A variant is not associated with breast cancer in African-American women. Cancer Genet Cytogenet 181: 16-19, 2008.

88. Majamaa K, Finnilä S, Turkka J and Hassinen IE: Mitochondrial DNA haplogroup $U$ as a risk factor for occipital stroke in migraine. Lancet 352: 455-456, 1998.

89. Finnila S, Hassinen IE and Majamaa K: Phylogenetic analysis of mitochondrial DNA in patients with an occipital stroke: Evaluation of mutations by using sequence data on the entire coding region. Mutat Res 458: 31-39, 2001.

90. Montiel-Sosa F, Ruiz-Pesini E, Enríquez JA, Marcuello A, Díez-Sánchez C, Montoya J, Wallace DC and López-Pérez MJ: Differences of sperm motility in mitochondrial DNA haplogroup U sublineages. Gene 368: 21-27, 2006.

91. Torroni A, Huoponen K, Francalacci P, Petrozzi M, Morelli L, Scozzari R, Obinu D, Savontaus ML and Wallace DC: Classification of european mtDNAs from an analysis of three European populations. Genetics 144: 1835-1850, 1996.

92. Torroni A, Carelli V, Petrozzim M, Terracina M, Barboni P, Malpassi P, Wallace DC and Scozzari R: Detection of the mtDNA 14484 mutation on an African-specific haplotype. Implications about its role in causing Leber hereditary optic neuropathy. Am J Hum Genet 59: 248-252, 1996.

93. Hutchin T and Cortopass G: A mitochondrial DNA clone is associated with increased risk for Alzheimer disease. Proc Natl Acad Sci USA 92: 6892-6895, 1995.

94. Zeviani M and Di Donato S: Mitochondrial tRNA mutations and disease. Brain 127: 2153-2172, 2004.

95. Maniura-Weber K, Helm M, Engemann K, Eckertz S, Mollers M, Schauen M, Hayrapetyan A, von Kleist-Retzow JC, Lightowlers RN, Bindoff L A and Wiesner RJ: Molecular dysfunction associated with the human mitochondrial 3302A $>\mathrm{G}$ mutation in the MTTL1 (mt-tRNA ${ }^{\mathrm{Leu}(\mathrm{UUR})}$ ) gene. Nucleic Acids Res 34: 6404-6415, 2006.

96. Bianchi NO, Bianchi MS and Richard SM: Mitochondrial genome instability in human cancers. Mutat Res 488: 9-23, 2001.

97. Kumimoto Y, Yamane Y Nishimoto H, Fukami M, Shinoda S, Hatooka K and Ishizaki K: Frequent somatic mutations of mitochondrial DNA in esophageal squamous cell carcinoma. Int J Cancer 108: 228-231, 2004.

98. Attardi G, Yoneda M and Chomyn A: Complementation and segregation behavior of disease-causing mitochondrial DNA mutations in cellular model systems. Biochim Biophys Acta 1271: 241-248, 1995.

99. Kaplan NL, Hudson RR and Langley $\mathrm{CH}$ : The 'hitchhiking effect' revisited. Genetics 123: 887-889, 1989.

100. Hofhaus G and Gattermann N: Mitochondria harbouring mutant mtDNA-a cuckoo in the nest? Biol Chem 380: 871-877, 1999. 